\title{
RESÍDUOS ELETRÔNICOS: CONSCIENTIZAÇÃO, CAMPANHAS E BENEFÍCIOS SOCIOAMBIENTAIS
}

\author{
Sthefani Ledy Fiuza Santos ${ }^{1}$ \\ Gilmar Oliveira Santos ${ }^{2}$ \\ Raisa Gomes Diniz ${ }^{3}$
}

Resumo: Em decorrência da revolução tecnológica, houve aumento significativo na comercialização de eletrônicos. Sendo assim, o objetivo deste trabalho foi promover a coleta desses resíduos e promover a conscientização nos alunos de uma escola pública. As campanhas foram realizadas através de coleta de resíduos, palestras e aplicação de questionários para verificar o nível de conhecimento sobre o assunto em dois momentos. Recolheu-se $674 \mathrm{~kg}$ de resíduos eletrônicos, envolvendo doadores externos e houve evolução nos acertos das questões após a palestra. O estímulo a competição e o exemplo dado através das palestras e incentivos dos servidores, favoreceu a condução e sucesso do projeto, onde todos ganharam de forma direta e indireta.

Palavras-chave: Educação Ambiental; Destinação Final; Metais Tóxicos; Reciclagem; Recolhimento.

${ }^{1}$ Universidade de Rio Verde. E-mail: sthefaniiledy@hotmail.com.

2 Universidade de Rio Verde. E-mail: gilmar@unirv.edu.br.

3 Universidade de Rio Verde. E-mail: raisadiniz@hotmail.com.

Revbea, São Paulo, V. 14, № 3: 238-251, 2019. 


\section{Introdução}

Um dos grandes problemas ambientais da atualidade, se dá a partir da enorme quantidade e os tipos de resíduos sólidos gerados, devido ao crescimento da população e a procura por produtos que atendam suas necessidades (SPENGLER; NUNES; FERREIRA, 2018) gerando assim cada vez mais resíduos. Para Santos e Fehr (2007), o progresso nos modos e hábitos de vida da população, geram um consumo exagerado e uma maior exigência na qualidade do produto.

Portanto, em decorrência da revolução tecnológica, houve aumento significativo na produção e comercialização de resíduos eletrônicos e os consumidores são incentivados a trocar seus aparelhos constantemente (LIMA et al., 2015). Somente no ano de 2018, está previsto o descarte de 4.800 toneladas de resíduo eletrônico, 70\% a mais do que no ano de 2009 (ONU BR, 2018).

O tratamento e a destinação final deste tipo de resíduo, envolvem soluções rápidas, como o simples descarte que, na maioria das vezes, acaba sendo em lixões deteriorando ainda mais o ambiente, além de abranger aspectos estéticos, administrativos, econômicos, sociais e a saúde pública (SIQUEIRA; MARQUES, 2012).

A falta de fiscalização diante das políticas de logística reversa, reciclagem, reutilização e doação de resíduos eletrônicos acarretam danos ao meio ambiente, já que os resíduos eletrônicos são constituídos por diversos tipos de metais e componentes químicos, o que os tornam ainda mais poluentes do que o resíduo comum, provocando significantes prejuízos ao meio ambiente (MOl et al., 2012).

Os impactos ocasionados por este tipo de resíduo colocam em risco a fauna e flora existentes no ambiente, bem como tudo a sua volta, sendo capaz de atingir grandes regiões (TANAUE et al., 2015). Esse fato é ocasionado devido sua composição conter vidro, plástico e metal e também metais tóxicos como níquel, cobre, cádmio que podem acumular no organismo dos seres vivos e os afetar (LIMA et al., 2015).

Por isso, é indispensável a implantação de procedimentos que assegurem a logística reversa do resíduo eletrônico, ou seja, sua coleta, reciclagem e retorno ao fabricante como matéria prima (CELINSKI et al., 2013). De acordo com Leite, Lavez e Souza (2009) a logística reversa proporciona sustentabilidade e eficiência além do desagravo dos impactos ambientais ocasionados por esse tipo de resíduo.

Porém, esta prática ainda é incipiente nas empresas já que, exige planejamentos específicos com alto custo (VIEIRA, SOARES e SOARES, 2009). No entanto para Santos e Silva (2011) existe também a possibilidade de reciclagem ou recuperação de valor econômico dos resíduos eletrônicos, já que possuem uma quantidade significativa de metais preciosos no seu interior. 
Segundo Santos e Silva (2011) para que a reciclagem aconteça é importante que 0 consumidor tenha em sua consciência princípios sustentáveis, cuja suas atitudes e hábitos disponham estes resíduos em organizações de fluxos reversos. Exemplos disso são os fabricantes, órgãos públicos e empresas especializadas na coleta deste tipo de resíduo.

Nesse contexto a Educação Ambiental entra como uma ferramenta importantíssima já que é entendida como "os processos por meio dos quais o indivíduo e a coletividade constroem valores sociais, conhecimentos, habilidades, atitudes e competências voltadas para a conservação do meio ambiente, bem de uso comum do povo, essencial à sadia qualidade de vida $e$ sua sustentabilidade" (Lei n 9795/1999).

Por isso a Educação Ambiental infantil contribui para a conscientização e os princípios culturais que são conduzidos adiante com o intuito de propagar conhecimentos e de melhorar o ambiente (MARQUES; SANTOS, 2015). Já que no Brasil, devido aos encontros e debates, representantes do poder público e da educação criaram programas mostrando a importância da Educação Ambiental, principalmente no ensino fundamental (BERNARDES; PRIETO, 2010).

Dessa forma, a Educação Ambiental passa a ser uma peça fundamental na construção de um pensamento de desenvolvimento, com a utilização de forma sustentável dos recursos naturais privilegiando melhorias com igualdade social e equilíbrio ecológico (GASQUES et al., 2016).

Sendo assim, este trabalho teve como objetivo promover a coleta de resíduos eletrônicos e iniciar um processo de conscientização nos alunos de uma unidade escolar pública no município de Rio Verde, Goiás.

\section{Material e Métodos}

\section{Localização da área de estudo}

O município de Rio Verde situa-se no Sudoeste do estado de Goiás,

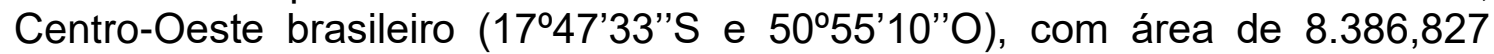
$\mathrm{km}^{2}$, população estimada de 217.048 habitantes (IBGE, 2017).

\section{Dados da escola}

O projeto foi realizado na Escola Municipal "Nestor Fonseca (EMEF)", no município de Rio Verde, Goiás, durante os meses de março a abril do ano de 2018, no turno matutino, com crianças do $3^{\circ}$ ao $5^{\circ}$ ano de 08 a 12 anos, totalizado 456 alunos, distribuídos em 14 salas de aula. 


\section{Campanha}

Foi realizada uma palestra sobre o tema: "Impactos sociais e ambientais ocasionados pelo descarte incorreto de resíduos eletrônicos", a todos os professores, funcionários e alunos do turno matutino da escola, as 14 turmas foram divididas em duas etapas para um melhor aprendizado dos alunos.

Na primeira etapa foi aplicado um questionário (Apêncice I) conforme proposto por Dias e Santos (2016) e Martins e Magalhães (2016), com seis perguntas objetivas de múltipla escolha com linguagem simples, a dois alunos aleatórios de cada turma, totalizando 28 alunos, para verificar qual a percepção das crianças em relação aos resíduos eletrônicos antes de ouvir a palestra. Após o questionário, foi ministrada uma palestra para todos os alunos e funcionários presentes.

Após a palestra, o questionário foi reaplicado a fim de avaliar o conhecimento absorvido pelas crianças sobre o descarte final de resíduos eletrônicos, já que é um tema pouco discutido e que tem grande importância social e ambiental.

$\mathrm{Na}$ segunda etapa, houve a campanha de coleta de resíduos, que foi realizada durante o período de dois dias alternados da semana de atividades escolares: terça-feira e quinta-feira para incentivar e reforçar a ideia de as crianças trazerem os resíduos eletrônicos de seus domicílios.

Foram recolhidos os seguintes resíduos: monitor, notebook, teclado, mouse, pilha, bateria, impressora, celular, calculadora, tablet, aparelhos de som, câmeras fotográficas, rádios, carregadores, fios e outros similares. Também foram recolhidos os resíduos eletrônicos da própria escola como forma de incentivar os funcionários do local a também trazerem seus resíduos ao longo do trabalho.

Desde o início da campanha foi proposto uma gincana, onde as três primeiras salas que mais pontuassem ganhariam um dia especial com lanches e filme ao término dela. Os alunos foram orientados sobre quais, resíduos poderiam ser levados para serem recolhidos com suas respectivas pontuações (Tabela 1). A pontuação foi definida pela autora.

A maior parte dos resíduos recolhidos, foram primeiramente levados até o domicílio de profissionais que, acompanharam toda a campanha. Os mesmos, trabalharam na desmontagem e retirada de metais preciosos (ouro, prata, paládio, cobre e alumínio) de seu interior, adquirindo uma renda extra com este tipo de serviço.

Posteriormente, todos os resíduos, foram transportados para a Cooperativa de Reciclagem do Sudoeste Goiano, que é o local apropriado para sua destinação dentro do município de Rio Verde, Goiás.

A confraternização com os alunos do turno matutino das três salas vencedoras foi realizada dentro da própria escola uma semana após o final da campanha e junto dela também aconteceram premiações. 


\section{Resultados e Discussão}

Durante a palestra ministrada foram abordadas imagens que evidenciaram a importância do descarte adequado dos resíduos eletrônicos. Também foi exposto o reaproveitamento deste tipo de resíduo através da reciclagem, esclarecendo aos participantes do que se tratava, quais são suas etapas e as suas principais vantagens (Figura 1).

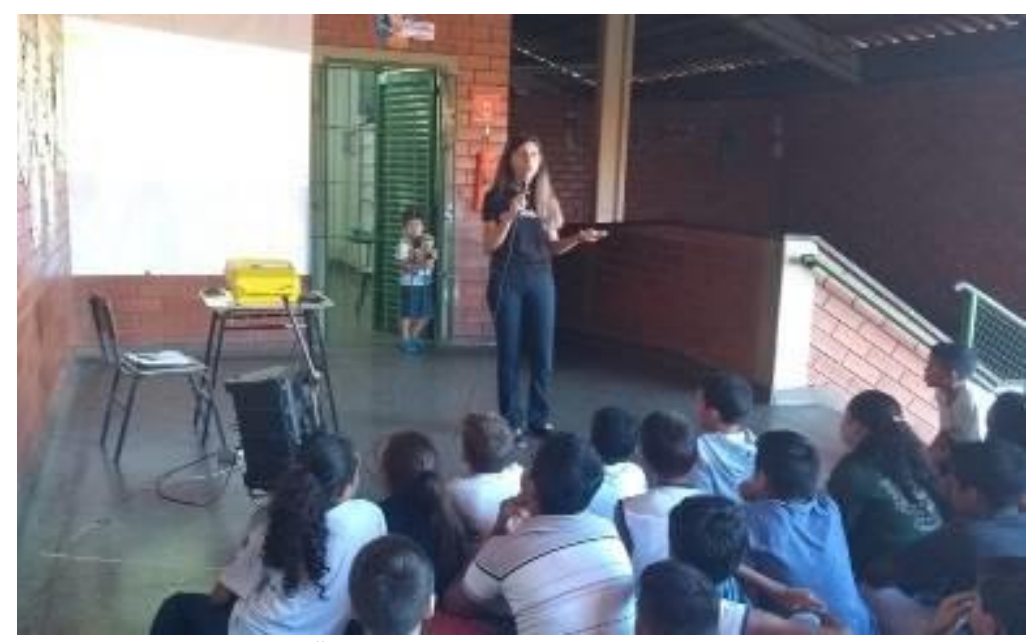

Figura 1. Palestra com o tema "Impactos sociais e ambientais ocasionados pelo descarte incorreto de resíduos eletrônicos” proferida aos alunos e funcionários da Escola Municipal de

Ensino Fundamental Nestor Fonseca (EMEF), Rio Verde, Goiás. Fonte: Autores (2018).

Durante a campanha, foi realizado o recolhimento dos resíduos em cada sala, nos dias estabelecidos durante o período de um mês (Figura 2).

a

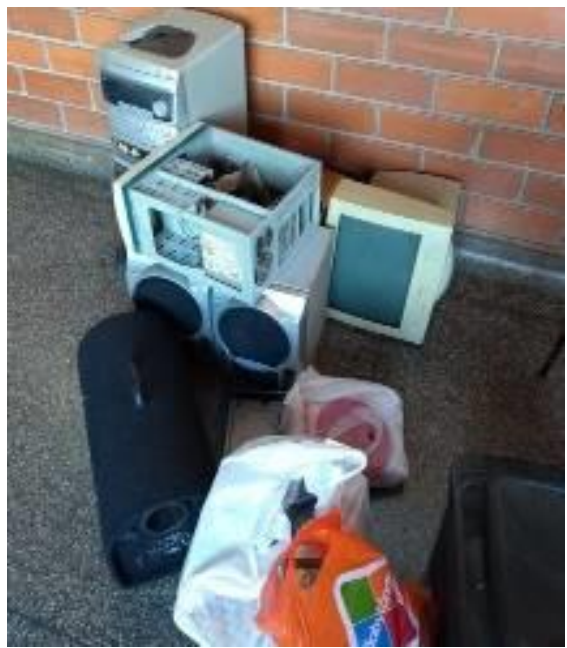

b

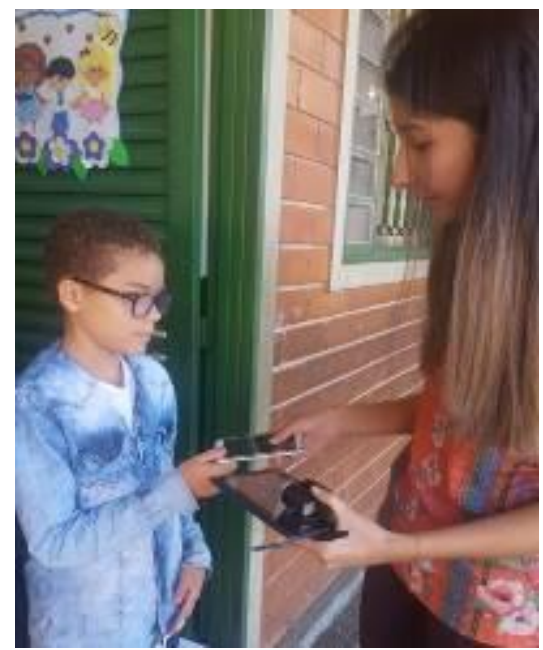

Figura 2. Alguns dos resíduos coletados na Escola Municipal de Ensino Fundamental Nestor Fonseca (EMEF), no município de Rio Verde, Goiás durante a campanha (a); Recolhimento dos resíduos feito em cada sala de aula (b). Fonte: Autores (2018). 
Os resíduos foram coletados e acondicionados em uma sala e posteriormente entregues ao centro de recolhimento de resíduos sólidos do município de Rio Verde.

O projeto "Cooperativa de Reciclagem do Sudoeste Goiano (COOP RECICLA)" do município de Rio Verde surgiu, a partir da necessidade da população em destinar seus resíduos sólidos de maneira adequada e assim oferecer benefícios para o meio ambiente além de ser uma fonte geradora de renda e trabalho.

Tabela 1: Resíduos eletrônicos aceitos na coleta realizada na Escola Municipal de Ensino Fundamental Nestor Fonseca (EMEF) em Rio Verde, Goiás no ano de 2018 e suas respectivas pontuações.

\begin{tabular}{cccc}
\hline Resíduo & Pontuação & Resíduo & Pontuação \\
\hline Aparelho de DVD & 25 & Gabinetes - CPU & 75 \\
Aparelho de fax & 20 & Geradores & 30 \\
Bateria de notebook & 75 & Hub & 25 \\
Bateria & 70 & Impressoras & 85 \\
Cable modem & 20 & Lanterna & 10 \\
Cabo & 15 & Leitor de cartões interno & 10 \\
Caixas de som & 50 & Leitor de CD e DVD & 25 \\
Calculadoras & 10 & Leitor de disquete & 20 \\
Câmera de segurança & 50 & Máquina de escrever & 55 \\
Câmera fotográfica & 35 & Memória de computador & 80 \\
CD/ DVD & 05 & Modem & 45 \\
Carregador de celular & 20 & Monitor CRT/LCD & 95 \\
Celular com bateria & 45 & Notebook & 90 \\
Celular sem bateria & 60 & Pilha & 05 \\
Central telefônica & 20 & Placas com ou sem ponteira & 80 \\
Controle remoto & 10 & Placas de circuito impresso & 85 \\
Controle de vídeo game & 10 & Placa de rede/ som/ vídeo & 90 \\
Conversor de canais & 70 & Peças internas de computador & 95 \\
Contator & 20 & Processador de computador & 100 \\
Conectores & 10 & Projetor multimídia & 80 \\
Copiadoras & 65 & Rádio & 40 \\
Decodificador & 20 & Relé & 35 \\
Disjuntor & 05 & Relógio & 15 \\
Drive CD/ DVD & 25 & Roteador & 40 \\
Eletrodomésticos & 90 & Scanner & 70 \\
Estabilizador & 80 & Tablet & 50 \\
Fios e cabos elétricos & 15 & Teclado e mouse & 35 \\
Fone de ouvido & 15 & Telefones & 40 \\
Fonte ATX & 10 & Transformadores & 30 \\
Fonte de notebook & 25 & TV & 35 \\
Fonte de energia & 10 & Vídeo-cassete & 35 \\
\hline & & &
\end{tabular}

Fonte: Os autores (2018).

Com o término da campanha, todos os resíduos recolhidos foram anotados individualmente e doados ao longo de toda sua duração para a Cooperativa de Reciclagem do Sudoeste Goiano - COOP RECICLA (Figura 3). 


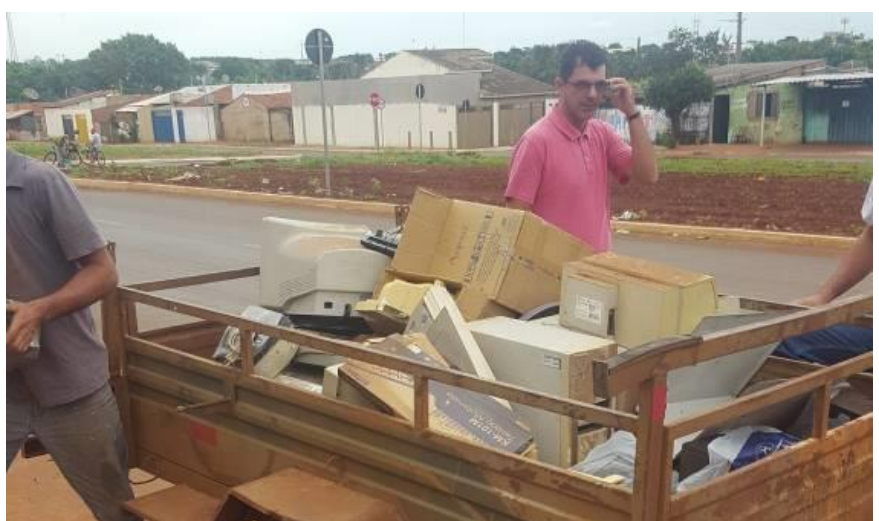

Figura 3. Ponto de coleta (COOP RECICLA) de resíduos eletrônicos no município de Rio Verde, Goiás recebendo os resíduos recolhidos durante o decorrer da campanha.

Fonte: Autores (2018).

A Cooperativa (COOP RECICLA) é pública e recebe todo o tipo de resíduos seco, até mesmo o resíduo eletrônico sendo que, depois que o resíduo é recolhido, é levado para a sede e depois vendido às usinas de reciclagem e tudo isso é feito por catadores, realizando assim um trabalho social.

Devido ao sucesso da divulgação da campanha de recolhimento dos resíduos eletrônicos na escola dentro das redes sociais, um cartório do município de Rio Verde se interessou e também quis participar descartando todo o resíduo eletrônico que estava guardado dentro do próprio local por bastante tempo. Por isso a Educação Ambiental é uma ferramenta importantíssima dentro da sociedade, já que foi disseminada pelos participantes da campanha e sensibilizou a população que teve acesso, transformando as atitudes destes indivíduos em relação ao meio ambiente.

A quantidade de resíduos recolhida durante toda a campanha dentro da unidade escolar totalizou $194 \mathrm{~kg}$ e no cartório que descartou os resíduos para a campanha foram $480 \mathrm{~kg}$ (Figura 4).

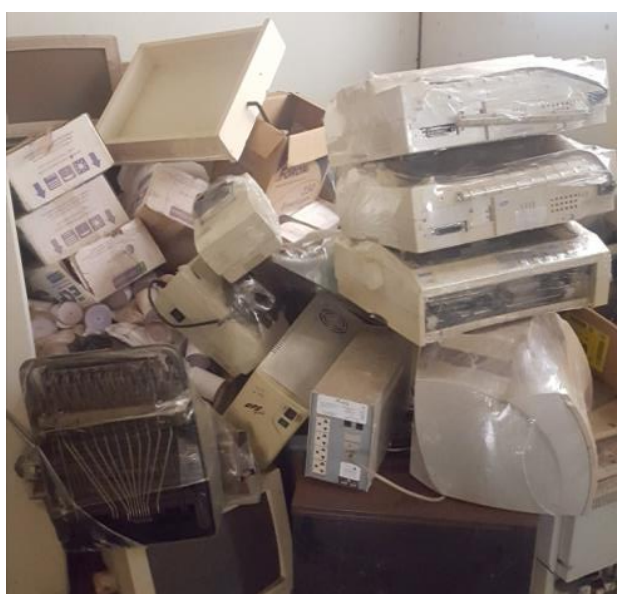

Figura 4. Resíduos eletrônicos que foram descartados e doados para a campanha pelo cartório de Rio Verde, Goiás. Fonte: Autores (2018). 
No total foram recolhidos $674 \mathrm{~kg}$ de resíduos eletrônicos com apenas um mês de campanha, isso evidencia a grande quantidade de resíduo eletrônico que é utilizada dentro da nossa sociedade e que seria descartada de maneira inadequada. Dentro da escola todos os resíduos foram anotados em quantidade de forma individual (Tabela 2).

Tabela 2. Descrição dos resíduos eletrônicos coletados durante toda a campanha.

\begin{tabular}{cccc}
\hline Resíduo & Quantidade & Resíduo & Quantidade \\
\hline Aparelho de DVD & 7 & Estabilizador & 1 \\
Bateria de notebook & 2 & Fios e cabos elétricos & 4 \\
Bateria & 171 & Fone de ouvido & 21 \\
Cabo & 31 & Fonte de notebook & 1 \\
Caixas de som & 13 & Gabinetes - CPU & 2 \\
Calculadora & 1 & Impressoras & 1 \\
& & & \\
Câmera de segurança & 2 & Leitor de cartões interno & 1 \\
Câmera fotográfica & 6 & Monitor CRT/ LCD & 9 \\
CD/ DVD & 1.221 & Pilha & 155 \\
Carregador de celular & 68 & Placas de circuito impresso & 16 \\
Celular com bateria & 46 & Processador de computador & 3 \\
Celular sem bateria & 97 & Rádio & 1 \\
Controle remoto & 39 & Relógio & 12 \\
Controle de vídeo game & 8 & Tablet & 18 \\
Conversor de canais & 7 & Teclado e mouse & 6 \\
Disjuntor & 1 & Telefones & 4 \\
Eletrodomésticos & 24 & TV & 7 \\
\hline
\end{tabular}

Fonte: Os autores (2018).

A confraternização com os alunos do turno matutino das três salas que mais se empenharam na campanha foi realizada na escola uma semana após o término da gincana, com a contribuição do Campeão Supermercado, localizado em Rio Verde, que doou a parte do lanche sendo de grande relevância para o trabalho (Figura 5a).

Também foi premiado cada aluno das 14 salas de aula que mais contribuíram na doação dos resíduos, como forma de agradecimento e também para incentivá-los a dar continuidade no que eles aprenderam durante a campanha (Figura 5b). 
a

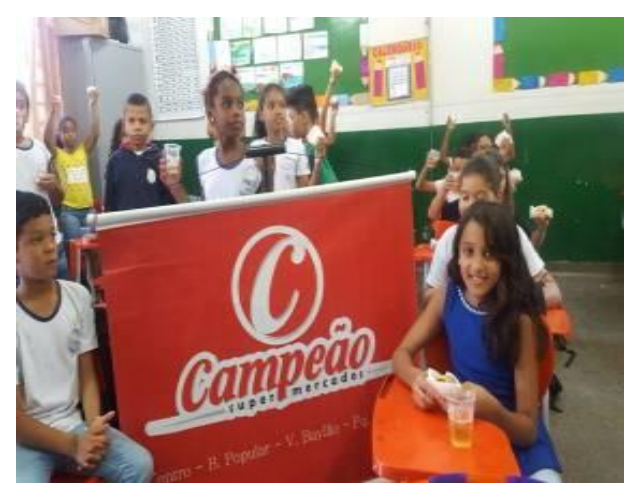

b

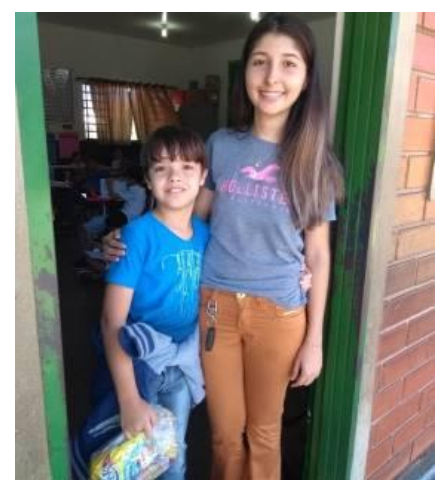

Figura 5. Lanche doado pelo Campeão Supermercado do município de Rio Verde, Goiás sendo distribuído para as salas vencedoras (a); Entrega da premiação para os alunos de cada sala que mais contribuíram com a campanha (b). Fonte: Autores (2018).

Através dos questionários iniciais e após a palestra, os alunos demonstraram ter conhecimento sobre o tema resíduo eletrônico, sendo que $75 \%$ dos alunos obtiveram êxito na questão 1 (Figura $6 a$ ), tanto no questionário inicial, quanto no questionário após a palestra. Isso evidencia o sucesso na atividade de Educação Ambiental realizada na escola, e o conhecimento e interesse dos alunos sobre este assunto.

Os participantes responderam satisfatoriamente à questão 2 "Na sua opinião, você faz parte do meio ambiente", obtendo $70 \%$ de acertos nos questionários aplicados antes e após a palestra (Figura 6b). Isso demonstra conhecimento por parte dos alunos e a importância da Educação Ambiental dentro da sala de aula já que este assunto não era o tema principal da palestra.

a

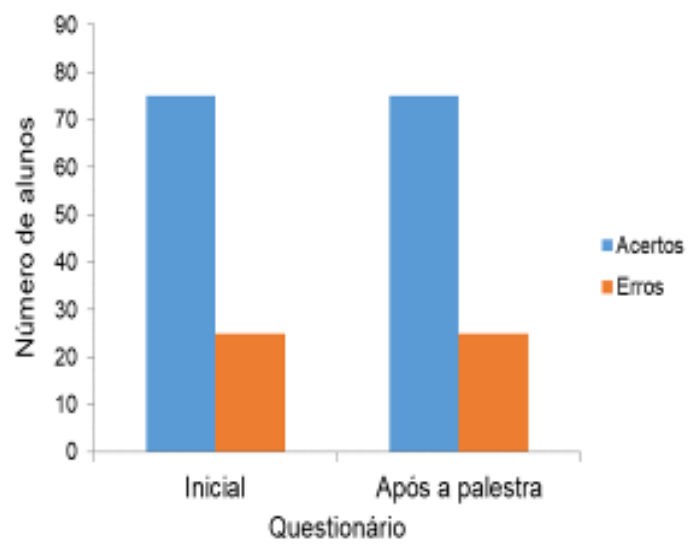

b

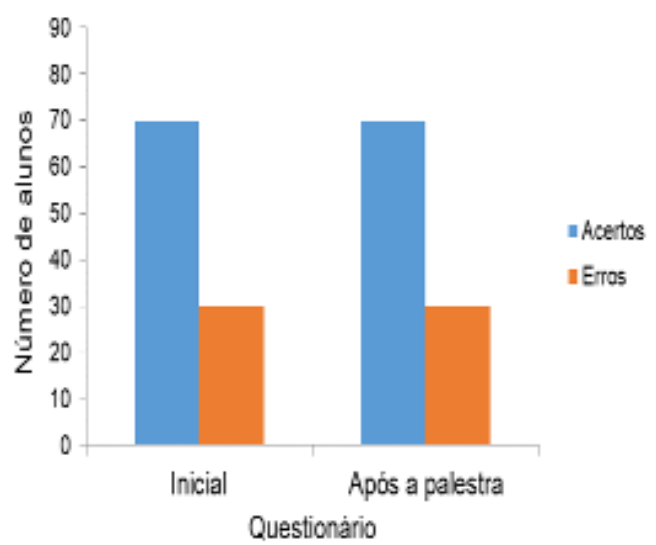

Figura 6. Quantidade de acertos inicial e após a intervenção da palestra em relação à questão 1 "Você sabe para que serve a Educação Ambiental? " (a) e questão 2 "Na sua opinião, você faz parte do meio ambiente?" (b). Fonte: Autores (2018). 
Nos resultados da questão 4, antes da palestra os alunos se mostraram indecisos sobre as opções de onde era descartado o resíduo eletrônico de seus domicílios, somando $55 \%$ de acertos, obtendo um aumento de $25 \%$ após a participação deles na palestra (Figura 7b).

Em relação à questão 5 envolvendo as consequências dos resíduos eletrônicos para o meio ambiente (Figura 8a), os acertos foram de 65\% antes da palestra e aumentaram $20 \%$ após a intervenção da palestra em relação ao questionário inicial, evidenciando a intervenção e importância da Educação Ambiental dentro deste assunto.

Na questão 6, nota-se a transformação do conhecimento dos alunos em relação a destinação adequada dos resíduos eletrônicos. No questionário inicial foi obtido $70 \%$ de acertos, sendo que este número aumentou $15 \%$ após a palestra, pelo que foi designado que eles fizessem nos dias da campanha (Figura 8b).

a

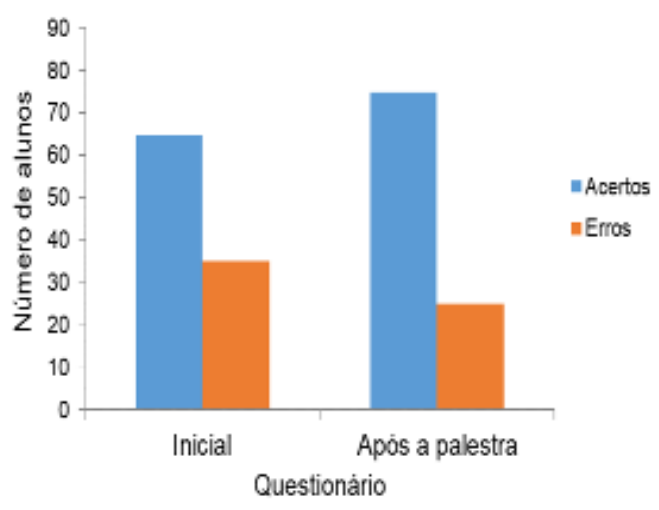

b

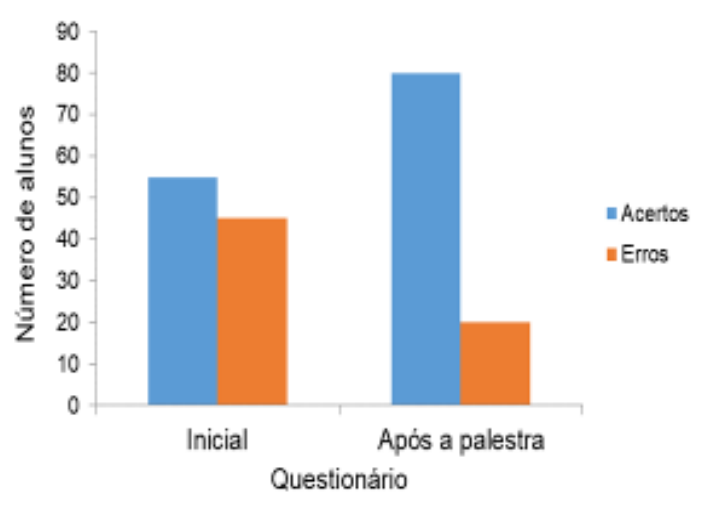

Figura 7. Quantidade de acertos inicial e após a intervenção da palestra em relação a questão 3 "O que você entende sobre resíduo eletrônico?" (a) e questão 4 "Qual é o local que as pessoas da sua casa descartam o resíduo eletrônico?" (b). Fonte: Autores (2018).

a

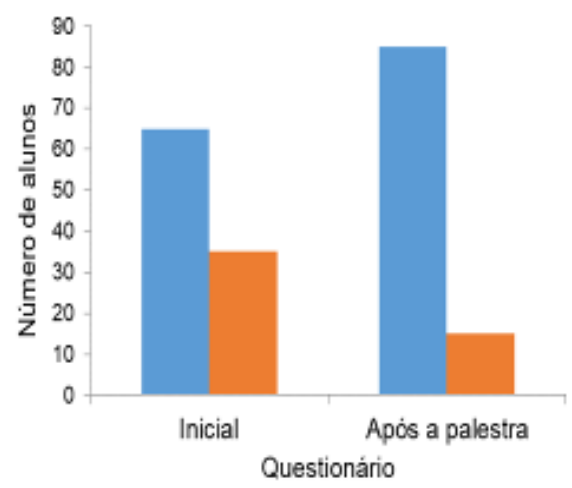

b

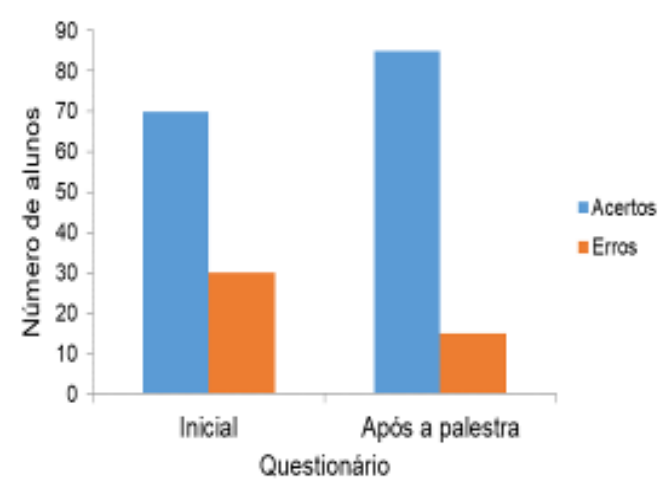

Figura 8. Quantidade de acertos inicial e após a intervenção da palestra em relação à questão 5 "Você acha que os resíduos eletrônicos trazem problemas para o meio ambiente e os seres vivos?" (a) e questão 6 "Qual você acha que seria a destinação adequada para os resíduos eletrônicos?" (b). Fonte: Autores (2018). 
A partir disso é possível obter uma possível reflexão, de que quando são trabalhados sobre Educação Ambiental e meio ambiente, os alunos entendem bem esses conceitos e vivenciam isso em seu próprio ambiente escolar, já que eles mesmos estão envolvidos com o meio ambiente (MACHADO; JUDICE, 2015).

Com a palestra e a gincana promovida na prática, os acadêmicos obtiveram maior consciência sobre a importância do descarte correto dos resíduos eletrônicos e as sérias consequências que estes resíduos podem trazer ao ambiente e a saúde humana quando descartados de maneira inadequada.

A campanha também sensibilizou um empreendimento do município de Rio Verde, que se propôs a doar todo o seu resíduo eletrônico que não era mais utilizado, o que mostrou a importância dada para este assunto dentro da nossa sociedade, a escola também abriu espaço para toda a população participar divulgando a campanha em rede social.

O incentivo dos professores e de toda a rede escolar é de extrema importância na formação de um futuro melhor para nossa comunidade. E esta campanha só foi possível devido ao grande empenho dos professores e alunos da unidade escolar, o que foi surpreendente já que este assunto não faz parte do cotidiano escolar destas pessoas.

É sugerida a continuação deste projeto através de projetos de leis que podem ser propostos por vereadores, não somente na escola, mas que envolva toda a sociedade já que o nosso município possui capacidade para isso, e por ser um tema totalmente novo dentro da nossa sociedade.

\section{Conclusões}

A campanha de recolhimento dos resíduos eletrônicos, envolveu de forma direta alunos, professores e funcionários da escola e por isso foi de grande importância, principalmente para os estudantes que se empenharam a descartar os resíduos para que a sala deles fossem a vencedora.

O estímulo a competição e o exemplo dado através das palestras e incentivos dos servidores, favoreceu a condução e sucesso do projeto, onde todos ganharam de forma direta e indireta.

Tudo isso possibilitou conhecimento sobre os perigos dos resíduos eletrônicos que, a princípio, parecem inofensivos. Fato este que ficou evidente nos questionários que foram aplicados inicialmente e após a palestra, já que houve evolução nos acertos das questões que envolviam o tema resíduo eletrônico. 


\section{Agradecimentos}

Ao Campeão Supermercados em Rio Verde pela doação de parte do lanche as crianças e servidores da unidade escolar.

\section{Referências}

BERNARDES, M. B. J.; PRIETO, E. C. Educação Ambiental: disciplina versus tema transversal. Revista eletrônica do Mestrado em Educação Ambiental, v.24, 2010, p. 173-185.

BRASIL. Lei no 9.795, Art. 01, de 27 de abril de 1999. Política Nacional de Educação Ambiental.

CELINSKI, T. M.; CERUTTI, D. M. L.; IELO, G. P. F.; CELINSKI, V. G.; CERUTII, I. A. Gestão do Lixo Eletrônico: Desafios e Oportunidades. In: Congresso Brasileiro de Gestão Ambiental, Salvador. Anais... Salvador: IBEAS, 2013, p. 1-4.

DIAS, T. P.; SANTOS, G. O. Educação Ambiental aplicada a produção de adubo orgânico em uma unidade escolar. Trabalho de Conclusão de Curso (Graduação) - Faculdade de Engenharia Ambiental, Universidade de Rio Verde - UniRV, Rio Verde, 2016.15 p.

GASQUES, A. C. F.; OKAWA, C. M. P.; SANTOS, J. D.; GASQUES, E. G. F.; DELABIO, F. Educação Ambiental: estudo de caso em dois colégios estaduais da cidade de Sarandi (PR). Revista Brasileira de Educação Ambiental, v.11, n.5, 2016, p. 123-138.

IBGE. Instituto Brasileiro de Geografia e Estatística. População estimada em 2017. Disponível em: <https://cidades.ibge.gov.br/brasil/go/rio-verde/ panorama>. Acesso: 17 out. 2017.

LEITE, P. R.; LAVEZ, N.; SOUZA, V. M. Fatores da logística reversa que influem no reaproveitamento do "lixo eletrônico" - Um estudo de caso no setor de informática. In: Simpósio de Administração da Produção Logística e Operações Internacionais, São Paulo. Anais... São Paulo: FGV, 2009, p. 1-16.

LIMA, A.F.O.; SABIÁ, R.J.; TEIXEIRA, R.N.P.; SOBREIRA Jr., F.A.V. Gestão de resíduos eletroeletrônicos e seus impactos na poluição ambiental. Revista Latin American Journal of Business Management, v.6, n.2, 2015, p.109-112.

MACHADO, A. J. S.; JUDICE, M. G. Difusão da Educação Ambiental através da implantação de horta escolar. Trabalho de Conclusão de Curso (Graduação) - Faculdade de Engenharia Ambiental, Universidade de Rio Verde - UniRV, Rio Verde, 2015, 12 p.

MARQUES, A.C.C.; SANTOS, G.O. Educação Ambiental em escolas no município de Cachoeira Alta - GO. Trabalho de Conclusão de Curso (Graduação) - Faculdade de Engenharia Ambiental, Universidade de Rio Verde - UniRV, Rio Verde, 2015, 15p. 
MARTINS, L. M.; MAGALHÃES, P. A. N. R. Educação Ambiental em escolas do ensino fundamental rural no município de Rio Verde - GO. Trabalho de Conclusão de Curso (Graduação) - Faculdade de Engenharia Ambiental, Universidade de Rio Verde - UniRV, Rio Verde, 2016.16p.

MOI, P. C. P.; SOUZA, A. P. S.; OLIVEIRA, M. M.; FAITTA, A. C. J.; REZENDE, W. B.; MOI, G. P.; FREIRE, F. A. L. Lixo eletrônico: consequências e possíveis soluções. Revista eletrônica Connection Line, n.7, 2012, p.37-45.

ORGANIZAÇÃO DAS NAÇÕES UNIDAS NO BRASIL (ONU BR). 2018. Disponível em: <https://nacoesunidas.org/acao-do-banco-mundial-com-eletrobras-tra nsforma-lixo-eletronico-em-recursos-para-projetos-sociais/>.Acesso: 10/08/18.

SANTOS, C. A. F.; SILVA, T. N. Descompasso entre a consciência ambiental e a atitude no ato de descartar lixo eletrônico: a perspectiva do usuário residencial e de uma empresa coletora. In: Encontro da Associação Nacional de Pós Graduação e Pesquisa em Administração, 35, 2011, Rio de Janeiro. Anais... Rio de Janeiro: EnANPAD, 2011. p. 1-17.

SANTOS, H. M. N., FEHR, M. Educação Ambiental por meio da compostagem de resíduos sólidos orgânicos em escolas públicas de Araguari - MG. Revista Caminhos de Geografia, v.8, n.24, 2007, p. 163-183.

SIQUEIRA, V. S.; MARQUES, D. H. F. Gestão e descarte de resíduos eletrônicos em Belo Horizonte: algumas considerações. Revista Caminhos de Geografia, v.13, n.43, 2012, p. 174-187.

SPENGLER, A. I.; NUNES, J. G.; FERREIRA, D. M. M. Determinação da composição gravimétrica de resíduos sólidos de feira em Sorris - MT. In: Congresso Sul - Americano de Resíduos Sólidos e Sustentabilidade, 2018, Gramado. Anais... Gramado: IBEAS, 2018, p. 1-6.

TANAUE, A. C. B.; BEZERRA, D. M.; CAVALHEIRO, L.; PISANO, L. C. Lixo eletrônico: Agravos a Saúde e ao Meio Ambiente. Revista Ensaio e Ciência: Biológicas, Agrárias e da Saúde, v.19, n.3, 2015, p. 130-134.

VIEIRA, K. N.; SOARES, T. O. R.; SOARES, L. R. A Logística Reversa do Lixo Tecnológico: um estudo sobre o projeto de coleta de lâmpadas, pilhas e baterias da BRASKEN. Revista de Gestão Social e Ambiental, v.3, n.3, 2009, p. $120-136$. 


\section{APÊNDICE I}

QUESTÃO 1) Você sabe para que serve a Educação Ambiental?

a) Para educar as pessoas;

b) Para ensinar o meio ambiente;

c) Para ensinar as pessoas sobre o meio ambiente:

d) Para ensinar os pais a educarem seus filhos.

QUESTÃO 2) Na sua opinião, você faz parte do meio ambiente?

a) Sim, pois no meio ambiente está incluso toda a vegetação, animais, microrganismos, solo, rochas, atmosfera, fenômenos naturais e todas as coisas vivas e não vivas ocorrendo na Terra;

b) Não, pois apenas fazem parte os animais;

c) Sim, pois apenas seres vivos fazem parte do meio ambiente;

d) Não, pois apenas fazem parte as plantas.

QUESTÃO 3) O que você entende sobre resíduo eletrônico?

a) Lixo eletrônico é qualquer tipo de resíduo que foi utilizado;

b) Lixo eletrônico são resíduos provenientes pelo descarte de restos de comida;

c) Lixo eletrônico é todo resíduo material produzido pelo descarte de equipamentos eletrônicos;

d) Lixo eletrônico é produzido somente por insetos e plantas.

QUESTÃO 4) Qual é o local que as pessoas da sua casa descartam o resíduo eletrônico?

a) Ele é queimado;

b) Ele é separado dos outros resíduos domiciliares e levado para as empresas que compram este tipo de resíduo;

c) Ele é colocado junto com os outros resíduos e levado pelo caminhão de lixo;

d) Ele é jogado em um terreno vazio, perto da minha casa.

QUESTÃO 5) Você acha que os resíduos eletrônicos trazem problemas para o meio ambiente e os seres vivos?

a) Não, pois eles não são cortantes e nem perfurantes;

b) Sim, porque eles podem explodir com o tempo;

c) Não, porque eles vão ir para um local adequado;

d) Sim, porque eles possuem substância tóxicas em sua composição principalmente os metais pesados que podem acumular no solo e poluir as águas subterrâneas.

QUESTÃO 6) Qual você acha que seria a destinação adequada para os resíduos eletrônicos?

a) O local adequado para se fazer o descarte desse tipo de resíduo são em empresas que atuam na reciclagem e os locais que recolhem e fazem seu reaproveitamento;

b) O local adequado para descartar os resíduos eletrônicos é o aterro sanitário;

c) O local adequado para o descarte desse tipo de resíduos é qualquer lote vazio próximo a minha casa;

d) Esse tipo de resíduo pode ser apenas queimado. 